\title{
Using Data Envelopment Analysis for Ranking Suppliers in the Presence of Nondiscretionary Factors
}

\author{
Reza Farzipoor Saen \\ Department of Industrial Management, Management and Accounting Faculty, Islamic Azad University-Karaj Branch, Karaj, Iran, P. \\ O. Box: 31485-313 \\ Tel: 0098 (261) 4418144-6 \\ Fax: 0098 (261) 4418156 \\ E-mail: farzipour@yahoo.com
}

\begin{abstract}
Building on the closeness and long-term relationships between buyers and suppliers is critical success factor to establish the supply chain system. Therefore, supplier ranking problem becomes the most important issue to implement a successful supply chain system. Current models of suppliers ranking assume complete discretionary of decision making criteria and do not assume suppliers ranking in the conditions that some factors are nondiscretionary. This paper proposes a method for ranking suppliers in the presence of nondiscretionary factors. A numerical example demonstrates the application of the proposed method.
\end{abstract}

Keywords: Supply chain management, Suppliers ranking, Nondiscretionary factors, Data envelopment analysis

\section{Introduction}

Managing the purchasing task in the supply chain has been a challenge in the last decade for many corporations. The need to gain a global competitive edge on the supply side has increased substantially. Particularly for companies who spend a high percentage of their sales revenue on parts and material supplies, and whose material costs represent a larger portion of total costs, savings from supplies are of particular importance. Moreover, the emphasis on quality and timely delivery in today's globally competitive marketplace adds a new level of complexity to outsourcing and supplier ranking decisions. These, strongly urge for a more systematic and transparent approach to purchasing decision making, especially regarding the area of supplier ranking. Ranking the suppliers significantly reduces the purchasing cost and improves corporate competitiveness, which is why many experts believe that the supplier ranking is the most important activity of a purchasing 
department. Supplier ranking is the process by which suppliers are reviewed, evaluated, and chosen to become part of the company's supply chain. Shin et al. (2000) argue that several important factors have caused the current shift to single sourcing or a reduced supplier base. First, multiple sourcing prevents suppliers from achieving the economies of scale based on order volume and learning curve effect. Second, multiple supplier system can be more expensive than a reduced supplier base. For instance, managing a large number of suppliers for a particular item directly increases costs, including the labor and order processing costs to managing multiple source inventories. Meanwhile multiple sourcing lowers overall quality level because of the increased variation in incoming quality among suppliers. Third, a reduced supplier base helps eliminate mistrust between buyers and suppliers due to lack of communication. Fourth, worldwide competition forces firms to find the best suppliers in the world.

Discretionary models for evaluating the efficiency of suppliers assume that all criteria are discretionary, i.e., controlled by the management of each supplier and varied at its discretion. Thus, failure of a supplier to produce maximal output levels with minimal input consumption results in a decreased efficiency score. In any realistic situation, however, there may exist exogenously fixed or nondiscretionary criteria that are beyond the control of a management. Instances include snowfall or weather in evaluating the efficiency of maintenance units, soil characteristics and topography in different farms, number of competitors in the branches of a restaurant chain, age of facilities in different universities, and number of transactions (for a purely gratis service) in library performance. Banker and Morey (1986) illustrate the impact of exogenously determined inputs that are not controllable in an analysis of a network of fast food restaurants. In their study, each of the 60 restaurants in the fast food chain consumes six inputs to produce three outputs. The three outputs (all controllable) correspond to breakfast, lunch, and dinner sales. Only two of the six inputs, expenditures for supplies and expenditures for labor, are discretionary. The other four inputs (age of store, advertising level, urban/rural location, and presence/absence of drive-in capability) are beyond the control of the individual restaurant manager. Their analysis clearly demonstrates the value of accounting for the nondiscretionary character of these inputs explicitly in the Data Envelopment Analysis (DEA) models they employ; the result is identification of a considerably enhanced opportunity for targeted savings in the controllable inputs and targeted increases in the outputs. In the case of ranking of suppliers, distance and supply variety are generally considered nondiscretionary criterion.

The objective of this paper is to propose a method for ranking suppliers in the presence of nondiscretionary factors.

This paper proceeds as follows. In Section 2, literature review is presented. Proposed method for ranking suppliers in the presence of nondiscretionary factors is introduced in Section 3. Section 
4 summarizes the algorithm of suppliers ranking. Numerical example and managerial implications are discussed in Sections 5 and 6, respectively. Concluding remarks are discussed in Section 7.

\section{Literature review}

Some mathematical programming approaches have been used in the past. Vokurka et al. (1996) proposed to incorporate expert system technology into a decision-support framework. Their expert system integrates the judgment and expertise of purchasing professionals with the formal approaches of earlier works. Choy et al. (2002) presented an Intelligent Supplier Management Tool (ISMT) using the Case-Based Reasoning (CBR) and Neural Network (NN) techniques to select and benchmark suppliers. Humphreys et al. (2003) introduced a framework for integrating environmental factors into the supplier selection process. They developed a decision support tool which helps companies to integrate environmental criteria into their supplier selection process. Subsequently, a framework of the supplier selection process which incorporates environmental performance is developed. In their framework, the user should give weightings to the environmental categories in order to represent its importance in the analysis.

Weber (1996) demonstrated how DEA can be used to evaluate vendors on multiple criteria and identified benchmark values which can then be used for this purpose. Braglia and Petroni (2000) described a multiple attribute utility theory based on the use of DEA, aimed at helping purchasing managers to formulate viable sourcing strategies in the changing market place. Weber et al. (2000) presented an approach for evaluating the number of vendors to employ in a procurement situation using Multi-Objective Programming (MOP) and DEA. The approach advocates developing vendororder quantity solutions (referred to as supervendors) using MOP and then evaluating the efficiency of these supervendors on multiple criteria using DEA. Forker and Mendez (2001) proposed an analytical method for benchmarking using DEA that can help companies identify their most efficient suppliers, the suppliers among the most efficient with the most widely applicable Total Quality Management (TQM) programs, and those suppliers who are not on the efficient frontier but who could move toward it by emulating the practices of their "best peer" supplier(s). To select appropriate suppliers, Talluri et al. (2006) suggested a Chance-Constrained Data Envelopment Analysis (CCDEA) approach in the presence of multiple performance measures that are uncertain.

To perform the supplier assessment, Kwong et al. (2002) introduced a combined scoring method with fuzzy expert systems approach. Lin and Chen (2004) presented a fuzzy decision making framework for selecting the most favorable strategic supply chain alliance under limited evaluation resources. Chang et al. (2006) proposed a Fuzzy Multiple Attribute Decision Making (FMADM) method based on the fuzzy linguistic quantifier. Chen et al. (2006) presented a fuzzy decision making approach to deal with the supplier selection problem in supply chain system. They used 
linguistic values to assess the ratings and weights for the criteria. These linguistic ratings can be expressed in trapezoidal or triangular fuzzy numbers. Then, a hierarchy Multiple Criteria Decision Making (MCDM) model based on fuzzy sets theory is proposed to deal with the supplier selection problems in the supply chain system. According to the concept of the Technique for Order Preference by Similarity to Ideal Solution (TOPSIS), a closeness coefficient is defined to determine the ranking order of all suppliers by calculating the distances to the both Fuzzy Positive Ideal Solution (FPIS) and Fuzzy Negative Ideal Solution (FNIS) simultaneously.

Kahraman et al. (2003) used fuzzy Analytic Hierarchy Process (AHP) to select the best supplier firm providing the most satisfaction for the criteria determined. To solve the vendor selection problem with multiple objectives, Kumar et al. (2004) applied fuzzy goal programming approach. To incorporate the imprecise aspiration levels of the goals, they formulated a vendor selection problem as a fuzzy mixed integer goal programming that includes three primary goals: minimizing the net cost, minimizing the net rejections, and minimizing the net late deliveries subject to realistic constraints regarding buyer's demand, vendor's capacity, vendor's quota flexibility, purchasing value of items, budget allocation to individual vendor, etc. Ohdar and Ray (2004) evaluated the supplier's performance by adopting an evolutionary fuzzy system. One of the key considerations in designing the proposed system is the generation of fuzzy rules. A genetic algorithm-based methodology is developed to evolve the optimal set of fuzzy rule base, and a fuzzy inference system of the MATLAB fuzzy logic toolbox is used to assess the supplier's performance.

Bhutta and Huq (2002) illustrated Total Cost of Ownership (TCO) and AHP approaches and provided a comparison. They concluded that TCO is better suited to those situations where cost is of high priority and detailed cost data are available to make comparisons. In the case of AHP, it is better suited to solve and decide between suppliers when several conflicting goals exist and, though cost may be an important factor, it is not the overriding one. Dahel (2003) presented a multiobjective mixed integer programming approach to simultaneously determine the number of vendors to employ and the order quantities to allocate to these vendors in a multiple-product, multiple-supplier competitive sourcing environment.

Çebi and Bayraktar (2003) proposed an integrated model for supplier selection. In their model, supplier selection problem has been structured as an integrated Lexicographic Goal Programming (LGP) and AHP model including both quantitative and qualitative conflicting factors. Karpak et al. (2001) presented one of the "user-friendly" multiple criteria decision support systems-Visual Interactive Goal programming (VIG). VIG facilitates the introduction of a decision support vehicle that helps improve the supplier selection decisions. Hajidimitriou and Georgiou (2002) presented a quantitative model, based on the Goal Programming (GP) technique, which uses appropriate criteria to evaluate potential candidates and leads to the selection of the optimal partner (supplier). To take 
into account both cardinal and ordinal data in supplier selection, Wang et al. (2004) developed an integrated AHP and Preemptive Goal Programming (PGP) based methodology.

To decide the total ranking of the suppliers, Liu and Hai (2005) compared the weighted sum of the selection number of rank vote, after determining the weights in a selected rank. They presented a novel weighting procedure in place of pairwise comparison of AHP for selecting suppliers. They provided a simpler method than AHP that is called voting analytic hierarchy process, but which do not lose the systematic approach of deriving the weights to be used and for scoring the performance of suppliers. Arunkumar et al. (2006) proposed a GP model for supplier selection with quantity discounts. They converted the piecewise linear problem into an easier linear problem, thereby decreasing the complexity of the problem. Stadtler (2007) presented a linear mixed integer programming (MIP) model, which not only represents the all-units discount but also the incremental discount case. Furthermore, the objective function chosen resolves conflicts among proponents of a purely cost oriented and a cash flow oriented modeling approach.

Xia and Wu (2007) proposed an integrated approach of AHP improved by rough sets theory and multi-objective mixed integer programming to simultaneously determine the number of suppliers to employ and the order quantity allocated to these suppliers in the case of multiple sourcing, multiple products, with multiple criteria and with supplier's capacity constraints. Cakravastia and Takahashi (2004) proposed a multi-objective model to support the process of supplier selection and negotiation that considers the effect of these decisions on the manufacturing plan. The model also takes into account several theoretical concepts in the negotiation process: concession force, resistance force and effective alternatives. Dulmin and Mininno (2003) presented a proposal for applying a decision model to the final vendor-rating phase of a process of supplier selection. Their model uses a Multiple Criteria Decision Aid (MCDA) technique (PROMETHEE 1 and 2), with a high-dimensional sensitivity analysis approach. They tried to explain how an outranking method and PROMETHEE/GAIA techniques, provides powerful tools to rank alternatives and analyzed the relations between criteria or between decision makers.

Sha and Che (2006) presented a multi-phased mathematical approach called the Hybrid Multiphased-based Genetic Algorithm (HMGA) for supply chain network design. From the point of network design, the important issues are to find suitable and quality companies, and to decide upon an appropriate production/distribution strategy. It is based on various methodologies that embrace Genetic Algorithms (GAs), AHP, and the Multi-Attribute Utility Theory (MAUT) to simultaneously satisfy the preferences of suppliers and customers at each level of the supply chain network.

Ghodsypour and O'Brien (2001) developed a mixed integer nonlinear programming model to solve the multiple sourcing problem, which takes into account the total cost of logistics, including 
net price, storage, transportation and ordering costs. Ip et al. (2004) described the sub-contractor selection problem by a 0-1 integer programming with non-analytical objective function. Hong et al. (2005) proposed a supplier selection method to maintain a continuous supply-relationship with suppliers. They suggested a mathematical programming model that considers the change in supplier's supply capabilities and customer needs over a period in time.

Ustun and Demirtas (2008) developed an integrated approach of analytic network process (ANP) and multi-objective mixed integer linear programming (MOMILP). The integrated approach considers both tangible and intangible factors in choosing the best suppliers and defines the optimum quantities among selected suppliers to maximize the total value of purchasing (TVP), and to minimize the total cost and total defect rate and to balance the total cost among periods. The priorities are calculated for each supplier by using ANP. Gencer and Gürpinar (2007) used ANP in supplier selection. They evaluated the relations between supplier selection criteria in a systematic feedback.

Ross and Droge (2002) measured distribution center productivity in a large scale setting, and identified distribution centers with consistent best performance using facet analysis, and detected performance trends using window analysis of 4 years data. Talluri and Baker (2002) presented a multi-phase mathematical programming approach for effective supply chain design. More specifically, they developed and applied a combination of multi-criteria efficiency models, based on game theory concepts, and linear and integer programming methods.

Talluri and Narasimhan (2003) proposed a max-min productivity based approach that derives vendor performance variability measures, which are then utilized in a nonparametric statistical technique in identifying vendor groups for effective selection. Lasch and Janker (2005) described a multivariate analysis tool for managing a pool of engaged or future suppliers. A constructed ideal supplier serves as a reference to compare all suppliers by means of factor analysis method.

Youssef et al. (1996) developed a cost-based model to solve supplier selection problem. Chandra et al. (2005) presented a model for selecting suppliers with geographical location as a critical factor using a Dual-Matrix approach. Cakravastia et al. (2002) developed an analytical model of the supplier selection process in designing a supply chain network. The constraints on the capacity of each potential supplier are considered in the process. Azoulay-Schwartz et al. (2004) used Gittins indices to optimally select a supplier. Smith et al. (2006) presented a set of stochastic models that explicitly incorporate interaction between co-suppliers and the interaction between the suppliers' characteristics and the ordering policy used by the buyer. The results show that taking into account the ordering policy and the interaction effects it can induce can lead to co-supplier evaluations that can differ significantly from those obtained from existing models that do not consider these effects. 
However, all the aforementioned references are based on complete discretionary of decision making criteria and do not consider suppliers ranking in the conditions that some factors are nondiscretionary. Although, Liu et al. (2000) proposed to employ DEA (Banker and Moreys s (1986) model) for selecting the best suppliers in the presence of nondiscretionary criteria, but they did not introduce a model which ranks the suppliers in the presence of nondiscretionary criteria.

To the best of author's knowledge, there is not any reference that discusses suppliers ranking in the conditions that some factors are nondiscretionary.

\section{Proposed method for ranking suppliers in the presence of nondiscretionary factors}

To deal with nondiscretionary factors, Banker and Morey (1986) provided the first model. The most important advantage of Banker and Morey s model lies in the simultaneous introduction in the same DEA programme of all the variables relevant to the research. With respect to aforementioned advantages of Banker and Morey's model (1986), Banker and Morey's idea is used for ranking suppliers. Output-oriented model of Banker and Morey (1986) as a standard model for the inclusion of nondiscretionary outputs is presented as follows:

Suppose that the output variables may be partitioned into subsets of discretionary (D) and nondiscretionary $(\mathrm{N})$ variables. Thus,

$$
O=\{1,2, \ldots, s\}=O_{D} \cup O_{N}, \quad O_{D} \cap O_{N}=\Phi
$$

In addition, there is a set of $n$ suppliers (Decision Making Units (DMUs)), $\left\{\mathrm{DMU}_{j}: j=1,2, \ldots\right.$, $n$, which produce multiple outputs $y_{r j}(r=1,2, \ldots, s)$, by utilizing multiple inputs $x_{i j}(i=1,2, \ldots$, $m)$. In particular, $\mathrm{DMU}_{p}$ consumes $x_{i p}(i=1, \ldots, m)$, the amount of input $i$, to produce $y_{r p}(r=1, \ldots, s)$, the amount of output $r$. When a DMU is under evaluation, there is 


$$
\begin{aligned}
& \operatorname{Max} \quad \eta+\varepsilon\left(\sum_{i=1}^{m} t_{i}^{-}+\sum_{r \in D} t_{r}^{+}\right) \\
& \text {s.t. } \quad x_{i p}=\sum_{j=1}^{n} x_{i j} \lambda_{j}+t_{i}^{-}, \quad i=1, \ldots, m \\
& \eta y_{r p}=\sum_{j=1}^{n} y_{t j} \lambda_{j}-t_{r}^{+}, \quad r \in D \\
& y_{r p}=\sum_{j=1}^{n} y_{r j} \lambda_{j}-t_{r}^{+}, \quad r \in N \\
& t_{r}^{+}=0, \quad r \in N \\
& \lambda_{j} \geq 0, \quad j=1, \ldots, n \\
& t_{i}^{-} \geq 0, \quad i=1, \ldots, m \\
& t_{r}^{+} \geq 0, \quad r=1, \ldots, s
\end{aligned}
$$

where $\eta$ is radial output augmentation factor (eventually to become efficiency measure) and $\lambda=\left\{\lambda_{j}\right\}$ is vector of DMU loadings, determining "best practice" for the DMU being evaluated. It is to be noted that the $\eta$ to be maximized appears only in the constraints for which $r \in D$, whereas the constraints for which $r \in N$ operate only indirectly (as they should) because the output levels $y_{r p}$ are not subject to managerial control. The variable $t_{r}^{+}$is shortfall amount of output $r$ and $t_{i}^{-}$is excess amount of input $i$. The higher the value of objective function of model (1), the less efficient the DMU. For model (1), it is not relevant to maximize the proportional increase in the entire output vector. Such maximization should be determined only with respect to the subvector that is composed of discretionary outputs.

Omitting the column corresponding to $\mathrm{DMU}_{p}$, the $\mathrm{DMU}$ under consideration, the ranking model is obtained as follows (Jahanshahloo and Afzalinejad (2006)):

$$
\begin{array}{lll}
\min & w_{p}+1 \\
\text { s.t. } & \sum_{\substack{j=1 \\
j \neq p}}^{n} \lambda_{j} x_{i j} \leq x_{i p}+w_{p} \mathbf{1}, \quad(i=1, \ldots, m) \\
& \sum_{\substack{j=1 \\
j \neq p}}^{n} \lambda_{j} y_{r j} \geq y_{r p}-w_{p} \mathbf{1}, \quad(r=1, \ldots, s) \\
& \lambda_{j} \geq 0 \quad(j=1, \ldots, n)
\end{array}
$$

where $w_{p}$ is a free variable and $\mathbf{1}$ is a vector of ones. Model (2) by decreasing inputs and increasing outputs of the DMU under consideration by equal sizes, project it on the frontier. Simultaneous 
changes in input and output are equal in size because otherwise due to giving different preferences to them, the problem becomes a multi objective programming one and hence yielding a complex situation. Since the inputs and outputs are not homogeneous and scale of objective function in model (2) is depended on the units of measurement of input and output data, unit independence is obtained by normalization, e.g. dividing each input and output to the largest of them as one of the techniques for normalization.

In the meantime, outcome of output oriented version of DEA models is an efficiency score equal to one to efficient DMUs and more than one to inefficient DMUs. So, for inefficient DMUs a ranking is given but efficient DMUs can not be ranked. One problem that has been discussed frequently in the DMUs ranking literature, has been the lack of discrimination in DEA applications, in particular when there are insufficient DMUs or the number of inputs and outputs is too high relative to the number of DMUs. In the supplier selection problem a difficulty arises when attempting to identify the "best", when multiple candidates have an efficiency score of 1 . If a decision maker arbitrarily selects an efficient supplier, then there is a possibility that this system is a niche member performing well on few inputs and outputs, and doing poorly with a majority of input-output measures. To rank the suppliers, this calls for a DEA model so that the nondiscretionary criteria can be compensated by other discretionary criteria. The key to the proper mathematical treatment of a nondiscretionary variable lies in the observation that information about the extent to which a nondiscretionary output variable may be increased is not meaningful for the DMU manager. By combining ideas of models (1) and (2), the proposed model is presented as follows: 
$\max$

$$
\eta-w_{p}-1-\varepsilon\left(\sum_{i=1}^{m} t_{i}^{-}+\sum_{r \in D} t_{r}^{+}\right)
$$

s.t. $\quad \sum_{\substack{j=1 \\ j \neq p}}^{n} x_{i j} \lambda_{j}-w_{p} \mathbf{1}+t_{i}^{-}=x_{i p}, \quad(i=1, \ldots, m)$

$\sum_{\substack{j=1 \\ j \neq p}}^{n} y_{r j} \lambda_{j}+w_{p} \mathbf{1}-t_{r}^{+}=\eta y_{r p}, \quad(r \in D)$

$\sum_{\substack{j=1 \\ j \neq p}}^{n} y_{r j} \lambda_{j}+w_{p} \mathbf{1}-t_{r}^{+}=y_{r p}, \quad(r \in N)$

$t_{r}^{+}=0, \quad(r \in N)$

$\lambda_{j} \geq 0, \quad(j=1, \ldots, n)$

$t_{i}^{-} \geq 0, \quad(i=1, \ldots, m)$

$t_{r}^{+} \geq 0, \quad(r=1, \ldots, s)$

where $w_{p}$ and $\eta$ are free variables and $\mathbf{1}$ is a vector of ones. The higher the value of objective function of model (3), the less efficient the DMU. Model (3) ranks efficient DMUs in the presence of nondiscretionary factors. Since, the output levels $y_{r p}$ are not subject to managerial control, it is to be noted that the $\eta$ to be maximized appears only in the constraints for which $r \in D$. Note that constraints for which $r \in N$, operate only indirectly. The variable $t_{r}^{+}$is shortfall amount of output $r$ and $t_{i}^{-}$is excess amount of input $i$.

Since the inputs and outputs are not homogeneous and scale of objective function in model (3) is depended on the units of measurement of input and output data, unit independence is obtained by normalization, e.g. dividing each input and output to the largest of them as one of the techniques for normalization.

\section{The algorithm}

Discussions in Section 3 can be summarized as follows:

1. Normalize data set: divide each input and output to the largest related number of the input or output.

2. To determine efficient DMUs, run model (1) for each DMU: note that the outcome of model (1) is an efficiency score equal to one to efficient DMUs and more than one to inefficient DMUs. In other words, the higher the value of objective function of model (1), will result to less efficiency of the DMU under consideration. If the value of objective function equals to 1 , the DMU under consideration will be efficient. 
3. To select a DMU from those are efficient, if there is multiple efficient DMUs, model (3) is used for each efficient DMU: as addressed in the previous step, inefficient DMUs could be ranked easily but efficient DMUs can not be ranked. To obviate the lack of discrimination problem in efficiency scores, model (3) is applied.

4. Rank the DMUs in increasing order of their objective values: to sort the DMUs based on their efficiency scores, in this step, the DMUs are ranked in ascending order of their efficiency scores.

5. Select the DMU with the least objective value as the best candidate: in this step the best DMU (i.e., the DMU with the least efficiency score) is selected.

\section{Numerical example}

For illustration purposes, the problem of suppliers ranking is introduced. The data set for this example contains specifications on 12 suppliers. The performance measures utilized were cost, R\&D expenditures, and supplier variety (The inputs and outputs selected in this paper are not exhaustive by any means, but are some general measures that can be utilized to evaluate suppliers. In an actual application of this methodology, decision makers must carefully identify appropriate inputs and outputs measures to be used in the decision making process). Cost was used in some sense as input for the DEA model. R\&D expenditures and supplier variety were considered as outputs. Moreover, assume that supplier variety is a nondiscretionary variable, i.e., this factor is exogenously fixed and could not be increased by suppliers (at least in short-term). Table 1 depicts the supplier attributes.

Now, each input and output is divided by the largest related number of the input or output. Table 2 shows the normalized data set.

In Table 3, the efficiency results by using model (1) have been displayed. Since the value of objective function of suppliers 1,5 , and 7 are equal to 1 , so these suppliers are efficient. The problem now becomes selecting a supplier from those three. To select a supplier from the top three suppliers in Table 3, model (3) is used. In Table 4, the ranking results by using model (3) have been displayed. The suppliers have been ranked in increasing order of their objective values. As Table 4 shows, supplier 7 is the most efficient supplier and is the first candidate for selection.

\section{Managerial implications}

With the widespread use of manufacturing philosophies such as Just-In-Time (JIT), emphasis has shifted to the simultaneous consideration of multiple criteria in supplier selection process. In today's competitive operating environment, it is impossible to successfully achieve low cost, high 
quality products without having satisfactory suppliers. Thus, one of the most important procurement decisions is the selection and maintenance of the best suppliers.

Purchasing materials have long been recognized as a multi-criteria problem. The joint consideration of multiple criteria complicates the selection decision, even in the case of experienced purchase managers, because competing suppliers have different levels of success under multiple criteria. For example, the supplier with the lowest price in a given industry may not have the best delivery performance or product quality.

The supplier ranking approach developed in this paper includes a number of attractive features that are as follow:

- This paper proposed an approach capable of treating nondiscretionary factors that are beyond the control of a DMU manager.

- The proposed approach considers multiple criteria in the presence of nondiscretionary factors. This helps managers to select suppliers using a comprehensive approach that goes beyond just purchase costs.

- The proposed approach is computationally efficient and can be solved in a few seconds on a personal computer.

\section{Concluding remarks}

Many practitioners and researchers have presented the advantages of supply chain management. In order to increase the competitive advantage, many companies consider that a well-designed and implemented supply chain system is an important tool. Under this condition, building on the closeness and long-term relationships between buyers and suppliers is critical success factor to establish the supply chain system. Therefore, supplier ranking problem becomes the most important issue to implement a successful supply chain system. This paper proposed a method for ranking suppliers in the presence of nondiscretionary factors.

The problem considered in this study is at initial stage of investigation and many further researches can be done based on the results of this paper. Some of them are as follows:

Similar research can be repeated for the cases of imprecise data, stochastic data, and generally, suppliers ranking under uncertainty when some factors are nondiscretionary. Other potential extension to the methodology includes the case that some of the suppliers are slightly non- 
homogeneous. One of the assumptions of all the classical models of DEA is based on complete homogeneity of DMUs (suppliers), whereas this assumption in many real applications cannot be generalized. In other words, some inputs and/or outputs are not common for all the DMUs occasionally. Therefore, there is a need to a model that deals with these conditions.

\section{Acknowledgement}

The author wishes to thank the anonymous reviewer for valuable suggestions and comments.

\section{References}

Arunkumar N., Karunamoorthy L., Anand S., Ramesh Babu T. (2006), Linear Approach for Solving a Piecewise Linear Vendor Selection Problem of Quantity Discounts Using Lexicographic Method, The International Journal of Advanced Manufacturing Technology, Vol. 28, No. 11-12, pp. 1254-1260.

Azoulay-Schwartz R., Kraus S., Wilkenfeld J. (2004), Exploitation vs. Exploration: Choosing a Supplier in an Environment of Incomplete Information, Decision Support Systems, Vol. 38, No. 1, pp. 1-18.

Banker R.D., Morey R.C. (1986), Efficiency analysis for exogenously fixed inputs and outputs, Operations Research, Vol. 34, No. 4, pp. 513-521.

Bhutta K. S., Huq F. (2002), Supplier Selection Problem: a Comparison of the Total Cost of Ownership and Analytic Hierarchy Process Approaches, Supply Chain Management: An International Journal, Vol. 7, No. 3, pp. 126-135.

Braglia M., Petroni A. (2000), A Quality Assurance-Oriented Methodology for Handling TradeOffs in Supplier Selection, International Journal of Physical Distribution \& Logistics Management, Vol. 30, No. 2, pp. 96-111.

Cakravastia A., Takahashi K. (2004), Integrated Model for Supplier Selection and Negotiation in a Make-To-Order Environment, International Journal of Production Research, Vol. 42, No. 21, pp. 4457-4474. 
Cakravastia A., Toha I. S., Nakamura N. (2002), A Two-Stage Model for the Design of Supply Chain Networks, International Journal of Production Economics, Vol. 80, No. 3, pp. 231-248.

Çebi F., Bayraktar D. (2003), An Integrated Approach for Supplier Selection, Logistics Information Management, Vol. 16, No. 6, pp. 395-400.

Chandra S., Chen B., Chan W. M. (2005), Supplier Selection Using Dual-Matrix Approach in a JIT System, Proceedings of 14th International Conference for the International Association of Management of Technology, pp. 1-6.

Chang S. L., Wang R. C., Wang S. Y. (2006), Applying Fuzzy Linguistic Quantifier to Select Supply Chain Partners at Different Phases of Product Life Cycle, International Journal of Production Economics, Vol. 100, No. 2, pp. 348-359.

Chen C. T., Lin C. T., Huang S. F. (2006), A Fuzzy Approach for Supplier Evaluation and Selection in Supply Chain Management, International Journal of Production Economics, Vol. 102, No. 2, pp. 289-301.

Choy K. L., Lee W. B., Lo V. (2002), An Intelligent Supplier Management Tool for Benchmarking Suppliers in Outsource Manufacturing, Expert Systems with Applications, Vol. 22, No. 3, pp. 213224.

Dahel N. E. (2003), Vendor Selection and Order Quantity Allocation in Volume Discount Environments, Supply Chain Management: An International Journal, Vol. 8, No. 4, pp. 335-342.

Dulmin R., Mininno V. (2003), Supplier Selection Using a Multi-Criteria Decision Aid Method, Journal of Purchasing and Supply Management, Vol. 9, No. 4, pp. 177-187.

Forker L. B., Mendez D. (2001), An Analytical Method for Benchmarking Best Peer Suppliers, International Journal of Operations \& Production Management, Vol. 21, No. 1/2, pp. 195-209.

Gencer, C., Gürpinar, D. (2007), Analytic network process in supplier selection: A case study in an electronic firm, Applied Mathematical Modelling, Vol. 31, No. 11, pp. 2475-2486. 
Ghodsypour S. H., O'Brien C. (2001), The Total Cost of Logistics in Supplier Selection, Under Conditions of Multiple Sourcing, Multiple Criteria and Capacity Constraint, International Journal of Production Economics, Vol. 73, No. 1, pp. 15-27.

Hajidimitriou Y. A., Georgiou A. C. (2002), A Goal Programming Model for Partner Selection Decisions in International Joint Ventures, European Journal of Operational Research, Vol. 138, No. 3, pp. 649-662.

Hong G. H., Park S. C., Jang D. S., Rho H. M. (2005), An Effective Supplier Selection Method for Constructing a Competitive Supply-Relationship, Expert Systems with Applications, Vol. 28, No. 4, pp. 629-639.

Humphreys P. K., Wong Y. K., Chan F. T. S. (2003), Integrating Environmental Criteria into the Supplier Selection Process, Journal of Materials Processing Technology, Vol. 138, No. 1-3, pp. 349-356.

Ip W. H., Yung K. L., Wang D. (2004), A Branch and Bound Algorithm for Sub-Contractor Selection in Agile Manufacturing Environment, International Journal of Production Economics, Vol. 87, No. 2, pp. 195-205.

Jahanshahloo G. R., Afzalinejad M. (2006), A ranking method based on a full-inefficient frontier, Applied Mathematical Modelling, Vol. 30, No. 3, pp. 248-260.

Kahraman C., Cebeci U., Ulukan Z. (2003), Multi-Criteria Supplier Selection Using Fuzzy AHP, Logistics Information Management, Vol. 16, No. 6, pp. 382-394.

Karpak B., Kumcu E., Kasuganti R. R. (2001), Purchasing Materials in the Supply Chain: Managing a Multi-Objective Task, European Journal of Purchasing \& Supply Management, Vol. 7, No. 3, pp. 209-216.

Kumar M., Vrat P., Shankar R. (2004), A Fuzzy Goal Programming Approach for Vendor Selection Problem in a Supply Chain, Computers \& Industrial Engineering, Vol. 46, No. 1, pp. 69-85. 
Kwong C. K., Ip W. H., Chan J. W. K. (2002), Combining Scoring Method and Fuzzy Expert Systems Approach to Supplier Assessment: a Case Study, Integrated Manufacturing Systems, Vol. 13, No. 7, pp. 512-519.

Lasch R., Janker C. G. (2005), Supplier Selection and Controlling using Multivariate Analysis, International Journal of Physical Distribution \& Logistics Management, Vol. 35, No. 6, pp. 409425.

Lin C. W. R., Chen H. Y. S. (2004), A Fuzzy Strategic Alliance Selection Framework for Supply Chain Partnering under Limited Evaluation Resources, Computers In Industry, Vol. 55, No. 2, pp. 159-179.

Liu J., Ding F. Y., Lall V. (2000), Using Data Envelopment Analysis to Compare Suppliers for Supplier Selection and Performance Improvement, Supply Chain Management: An International Journal, Vol. 5, No. 3, pp. 143-150.

Liu F. F., Hai H. L. (2005), The Voting Analytic Hierarchy Process Method for Selecting Supplier, International Journal of Production Economics, Vol. 97, No. 3, pp. 308-317.

Ohdar R., Ray P. K. (2004), Performance Measurement and Evaluation of Suppliers in Supply Chain: an Evolutionary Fuzzy-Based Approach, Journal of Manufacturing Technology Management, Vol. 15, No. 8, pp. 723-734.

Ross A., Droge C. (2002), An Integrated Benchmarking Approach to Distribution Center Performance Using DEA Modeling, Journal of Operations Management, Vol. 20, No. 1, pp. 19-32.

Sha D., Che Z. (2006), Supply Chain Network Design: Partner Selection and Production/Distribution Planning using a Systematic Model, Journal of the Operational Research Society, Vol. 57, No. 1, pp. 52-62.

Shin H., Collier D. A., Wilson D. D. (2000), Supply Management Orientation and Supplier/Buyer Performance, Journal of Operations Management, Vol. 18, No. 3, pp. 317-333. 
Smith N. R., Garza D., Hasenbein J. J. (2006), Effect of Delivery Timing Interaction and Disasters on Co-Supplier Evaluation, International Journal of Production Research, Vol. 44, No. 9, pp. 1845-1862.

Stadtler, H. (2007), A general quantity discount and supplier selection mixed integer programming model, OR Spectrum, Vol. 29, No. 4, pp. 723-744.

Talluri S., Baker R. C. (2002), A Multi-Phase Mathematical Programming Approach for Effective Supply Chain Design, European Journal of Operational Research, Vol. 141, No. 3, pp. 544-558.

Talluri S., Narasimhan R. (2003), Vendor Evaluation with Performance Variability: A Max-Min Approach, European Journal of Operational Research, Vol. 146, No. 3, pp. 543-552.

Talluri S., Narasimhan R., Nair A. (2006), Vendor Performance with Supply Risk: a ChanceConstrained DEA Approach, International Journal of Production Economics, Vol. 100, No. 2, pp. 212-222.

Ustun, O., Demirtas, E. A. (2008), An integrated multi-objective decision-making process for multiperiod lot-sizing with supplier selection, Omega, Vol. 36, No. 4, pp. 509-521.

Vokurka R. J., Choobineh J., Vadi L. (1996), A Prototype Expert System for the Evaluation and Selection of Potential Suppliers, International Journal of Operations \& Production Management, Vol. 16, No. 12, pp. 106-127.

Wang G., Huang S. H., Dismukes J. P. (2004), Product-Driven Supply Chain Selection Using Integrated Multi-Criteria Decision-Making Methodology, International Journal of Production Economics, Vol. 91, No. 1, pp. 1-15.

Weber C. A. (1996), A Data Envelopment Analysis Approach to Measuring Vendor Performance, Supply Chain Management, Vol. 1, No. 1, pp. 28-39.

Weber C. A., Current J., Desai A. (2000), An Optimization Approach to Determining the Number of Vendors to Employ, Supply Chain Management: An International Journal, Vol. 5, No. 2, pp. 9098. 
Xia W., Wu Z. (2007), Supplier Selection with Multiple Criteria in Volume Discount

Environments, Omega, Vol. 35, No. 5, pp. 494-504.

Youssef M. A., Zairi M., Mohanty B. (1996), Supplier Selection in an Advanced Manufacturing Technology Environment: an Optimization Model, Benchmarking for Quality Management \& Technology, Vol. 3, No. 4, pp. 60-72.

Table 1. Related attributes for 12 suppliers

\begin{tabular}{|c|c||c|c|}
\hline \multirow{2}{*}{$\begin{array}{c}\text { Supplier } \\
\text { No. } \\
\text { (DMU) }\end{array}$} & Input & \multicolumn{2}{|c|}{ Cost } \\
\cline { 2 - 4 }$(1000 \$)$ & R\&D & Sutputs \\
\hline 1 & 800 & 60 & Supplier variety \\
\hline 2 & 1000 & 60 & 5 \\
\hline 3 & 905 & 45 & 1 \\
\hline 4 & 720 & 150 & 1 \\
\hline 5 & 960 & 500 & 2 \\
\hline 6 & 1700 & 100 & 5 \\
\hline 7 & 850 & 500 & 3 \\
\hline 8 & 980 & 150 & 1 \\
\hline 9 & 672 & 100 & 1 \\
\hline 10 & 700 & 60 & 1 \\
\hline 11 & 880 & 300 & 1 \\
\hline 12 & 900 & 136 & 5 \\
\hline
\end{tabular}

Table 2. Normalized data set

\begin{tabular}{|c|c||c|c|}
\hline $\begin{array}{c}\text { Supplier } \\
\text { No. } \\
\text { (DMU) }\end{array}$ & Input & \multicolumn{2}{|c|}{ Outputs } \\
\cline { 2 - 4 } & Cost & R\&D & Supplier variety \\
\hline 1 & .471 & .12 & 1 \\
\hline 2 & .588 & .12 & .2 \\
\hline 3 & .532 & .09 & .2 \\
\hline 4 & .424 & .3 & .4 \\
\hline 5 & .565 & 1 & 1 \\
\hline 6 & 1 & .2 & .6 \\
\hline 7 & .5 & 1 & .2 \\
\hline 8 & .576 & .3 & .2 \\
\hline 9 & .395 & .2 & .2 \\
\hline 10 & .412 & .12 & .2 \\
\hline 11 & .518 & .6 & .2 \\
\hline 12 & .529 & .272 & 1 \\
\hline
\end{tabular}


Table 3. Efficiency results

\begin{tabular}{|c|c|}
\hline $\begin{array}{c}\text { Supplier } \\
\text { No. } \\
\text { (DMU) }\end{array}$ & Efficiency \\
\hline 1 & 1 \\
\hline 2 & 8.3 \\
\hline 3 & 11.1 \\
\hline 4 & 2.7 \\
\hline 5 & 1 \\
\hline 6 & 9.8 \\
\hline 7 & 1 \\
\hline 8 & 3.3 \\
\hline 9 & 3.9 \\
\hline 10 & 6.8 \\
\hline 11 & 1.7 \\
\hline 12 & 2.4 \\
\hline
\end{tabular}

Table 4. Final solution

\begin{tabular}{|c|c|c|}
\hline $\begin{array}{c}\text { DMU } \\
\text { Rank }\end{array}$ & $\begin{array}{c}\text { Supplier No. } \\
\text { (DMU) }\end{array}$ & $\begin{array}{c}\text { Objective } \\
\text { value }\end{array}$ \\
\hline 1 & 7 & 0 \\
\hline 2 & 5 & 1.236 \\
\hline 3 & 1 & 20.763 \\
\hline
\end{tabular}

